\title{
O processo de representação política construído pelas igrejas pentecostais no Brasil (1985-2016)
}

\section{The Process of Building Political Representation in Pentecostal Churches in Brazil (1985-2016)}

\section{Luis Gustavo Teixeira da Silva*}

RESUMO: Este artigo tem como propósito discutir as formas de construção da representação política dos pentecostais para os cargos no Poder Legislativo brasileiro. Na primeira seção analisamos as razões da mobilização político-eleitoral das igrejas pentecostais e o processo de autorização política pelos eleitores/fiéis aos candidatos de suas denominações. Na segunda seção o enfoque se concentra na compreensão do modelo peculiar de representação políitica construído pelas igrejas pentecostais, por meio das estratégias mobilizadas para sua execução e a relação entre representante e representado. Por fim, 0 artigo se compromete a avaliar os riscos desta forma de atuação política das religiões à democracia brasileira.

Palavras-chave: Pentecostais; Representação; Poder Legislativo; Democracia; Brasil.

ABSTRACT: This article aims to discuss the forms of construction of the political representation of the Pentecostals for positions in the Brazilian Legislative Branch. In the first section we analyze the reasons for the political-electoral mobilization of the Pentecostal churches and the process of political authorization by the voters/believers to the candidates of their denominations. In the second section the focus is on the understanding of the peculiar model of political representation built by the Pentecostal churches, through the strategies mobilized for its execution and the relation between representative and represented. Finally, the article undertakes to evaluate the risks of this form of political action of the religions to the Brazilian democracy.

KeY words: Pentecostals; Representation; Congress Legislative Power; Democracy; Brazil.

Recibido: 1 de octubre de 2018

Aceptado: 24 de abril de 2019

Universidade Federal de Pelotas, Brasil (gustavoteixeira2519@gmail.com). 
INTRODUÇÃO

ascensão na política brasileira de parlamentares vinculados às
igrejas pentecostais ${ }^{1}$ tem mobilizado ampla atenção das/os pes-
quisadores, devido aos seus efeitos no sistema político, assim
como por seus contornos e variações singulares. Sendo assim, este artigo tem como propósito discutir as formas de construção da representação política dos pentecostais para os cargos no Poder Legislativo brasileiro.

Neste artigo realizamos dois recortes metodológicos, por um lado, examinamos apenas a construção da representação política no Poder Legislativo, pois esse processo ainda é incipiente no tocante ao Poder Executivo nas três esferas da federação. Por outro lado, realizamos um recorte no campo religioso denominado evangélico, ou seja, a análise compreende somente as igrejas pentecostais, neste caso excluímos considerações sobre as igrejas protestantes históricas, entre elas: Metodista, Luterana, Batista, Presbiteriana e Anglicana. Esse recorte se justifica pela ausência de evidências substanciais sobre a mobilização e elaboração de estratégias pelas igrejas protestantes com fins político-eleitorais para obter representação política.

Na primeira seção analisamos as razões da mobilização político-eleitoral das igrejas pentecostais. Nesta seção também examinamos o pro-

1 Esta terminologia foi elaborada por Paul Freston, em sua tese de doutorado, e designa os grupos remanescentes dos três grandes ciclos do pentecostalismo no Brasil. O primeiro ocorreu em meados de 1910, a partir das Igrejas Assembleia de Deus e Congregação Cristã. O segundo ciclo foi na década de 1950, em meio ao processo de urbanização do país, as principais igrejas são: Evangelho Quadrangular e Deus é Amor. As diferenças entre os dois ciclos são basicamente teológicas, enquanto no primeiro é introduzida no campo religioso a crença nos dons do espírito santo, o segundo é marcado pela crença na cura divina somado aos dons do espírito santo. Na década de 1970 emerge o terceiro ciclo. A Igreja Universal do Reino de Deus e a Igreja Internacional da Graça de Deus introduziram a teologia da prosperidade, o uso das mídias, do exorcismo e da inserção religiosa na política institucional. Neste texto vamos utilizar apenas a nomenclatura pentecostal já que ele é mais corrente em países da América Latina, porém especificando o nome das denominações. 
cesso de autorização política neste ambiente, com a finalidade de refletir sobre as variáveis explicativas para a adesão dos fiéis/eleitores aos postulantes a cargos políticos tutelados por suas denominações. Na segunda seção o enfoque se concentra na compreensão do modelo peculiar de representação política construído pelas igrejas pentecostais, por meio das estratégias mobilizadas para sua execução e a relação entre representante e representado. Por fim, o artigo se compromete a avaliar os riscos desta forma de atuação política das religiões à democracia brasileira. ${ }^{2}$

A CONSTRUÇÃO DA REPRESENTAÇÃO POLÍTICA

No contexto de abertura democrática, sobretudo durante a elaboração da Constituição de 1988, foi possível verificar a significativa presença e atuação de políticos vinculados, de algum modo, as denominações pentecostais. Este fenômeno ocorrido no processo de redemocratização se transformou em indicador preliminar sobre a emergência da influência de outra clivagem cristã, além da Igreja Católica, no ambiente da política institucional. A partir disso, nosso propósito agora é examinar as bases em que se constrói esse movimento de inserção de representantes associados às igrejas pentecostais nos espaços políticos.

Um dos principais eixos explicativos para a construção de iniciativas político-eleitorais pelos pentecostais neste período é derivado de conflitos com outros setores da sociedade, nomeadamente os partidos políticos à esquerda, a Igreja Católica e os veículos da comunicação. Três episódios emblemáticos forneceram incentivos para justificar a organização políti-

2 Este artigo é um dos resultados de meu trabalho na tese de doutorado, intitulada Sobre Corpos Crucifixos e Liberdades: a laicidade do Estado analisada a partir do debate legislativo sobre o aborto no Brasil e no Uruguai (1985-2016), sob orientação da Professora Flávia Biroli. A pesquisa foi realizada no âmbito do Instituto Democracia e Desigualdades da Universidade de Brasília, financiada pelas agências de fomento: Capes, CNPQ e FAPDF, com resultados e discussões preliminares já publicados em periódicos do Brasil. 
co-eleitoral, por conseguinte, legitimar a narrativa acerca da imprescindibilidade da representação política deste segmento religioso.

Conforme sustenta Ricardo Mariano, a mobilização dos pentecostais no contexto da redemocratização foi motivada pelo temor de que a ação política de setores da Igreja Católica ${ }^{3}$ aliados aos partidos de esquerda impusesse limites ao seu avanço religioso e social, por meio de interferências durante e/ou após a elaboração da Constituição de 1988.

Este temor foi decisivo para as alianças políticas construídas por algumas denominações. Por exemplo, nas eleições de 1989 e de 1994, os pentecostais apoiaram para o cargo de Presidente da República os candidatos Fernando Collor de Mello (Partido da Reconstrução Nacional-PRN) e Fernando Henrique Cardoso (Partido da Social Democracia Brasileira-PSDB), respectivamente (ambos foram eleitos), com o objetivo de firmar oposição ao candidato Luiz Inácio Lula da Silva (Partido dos Trabalhadores-PT). ${ }^{4}$

De acordo com as informações apresentadas por Ricardo Mariano e Antonio Pierucci, as lideranças pentecostais entendiam que havia uma aliança entre o Partido dos Trabalhadores (PT) e a Igreja Católica, para restringir a liberdade de culto dos pentecostais. ${ }^{5}$ Por esse motivo, as lideranças religiosas orientavam seus fiéis a evitar candidatos desta agremiação partidária, tanto para o Poder Executivo nacional, como aos executivos estaduais e cargos legislativos (nacional e regional). ${ }^{6}$

O apoio político das igrejas pentecostais sofreu uma profunda alteração a partir das eleições de 1998, quando muitas denominações apoiaram o candidato Lula (PT) à Presidência da República. Uma das explicações

3 Especialmente de setores vinculados as Comunidades Eclesiais de Base e a Teologia da Libertação.

4 O amplo apoio de diversas denominações a estes candidatos foi verificado principalmente no segundo turno das respectivas eleições, quando em ambos os casos o outro concorrente era Luiz Inácio Lula da Silva (PT).

5 O candidato Lula foi apoiado por várias igrejas protestantes históricas, tais como: Metodista, Episcopal, Presbiteriana, Luterana e Batista.

6 Desde 1989 as eleições no Brasil ocorrem em duas modalidades, na primeira são eleitos: Presidente da República, Governadores dos Estados, os deputados federais e estaduais, assim como uma parcela dos senadores. Na segunda modalidade são eleitos: Prefeitos e vereadores (legisladores) dos municípios. 
para a ruptura com o governo Fernando Henrique Cardoso (PSDB), que disputava a reeleição em 1998, foi às proposições políticas deste governo sobre direitos à população LGBTTQ e a flexibilização para realização do aborto em caso de violação sexual. Na eleição de 2002, os líderes religiosos do segmento assinaram um documento, intitulado "Manifesto dos Evangélicos",7 outorgando apoio ao candidato Lula e ao Partido dos Trabalhadores. A chamada "bancada evangélica", integrada por representantes de igrejas pentecostais e protestantes, compôs parte significativa da base de apoio parlamentar nos dois mandatos do Governo Lula (2003-2010). A ruptura ocorreu no Governo da Presidenta Dilma Rousseff (2011-2016), quando a "bancada evangélica" foi decisiva para seu processo de deposição do cargo.

O segundo episódio ocorreu no ano 1992, quando o Bispo Edir Macedo, líder da Igreja Universal do Reino de Deus, foi preso na cidade de São Paulo acusado de realizar atos de curandeirismo, estelionato e charlatanismo. Apesar das muitas divergências litúrgicas e de pensamento entre as denominações pentecostais, este episódio gerou comoção entre os fiéis e as lideranças, que na ocasião sinalizaram a junção de esforços para que no Brasil nenhum cristão fosse novamente preso por pregar o evangelho (estes aspectos são destacados no trabalho de Pedro Geraldo e também de Emerson Giumbelli). ${ }^{8}$

Por último, convém salientar a relação conflituosa entre as igrejas pentecostais e os meios de comunicação, sobretudo aqueles vinculados ao Grupo Globo. Isto dito, em virtude de algumas coberturas jornalísticas, consideradas pelos pentecostais com enquadramento distorcido dos

Líderes das igrejas: Universal, Assembleia de Deus, Sara Nossa Terra e Igreja da Graça. Assim como, líderes de igrejas protestantes, como: Batista, Anglicana, Presbiteriana, Luterana e Metodista.

8 No ano de 2014, o Bispo Edir Macedo publicou o livro "Nada a perder", no qual relata que sua prisão foi resultado de perseguição política e religiosa da Igreja Católica. Em passagem o bispo sublinha: "O Clero Romano mandava e desmandava no Brasil, mais do que nos dias de hoje [... . A Cúria não admitia o surgimento de um povo livre da escravidão religiosa imposta por eles" (13). 
fatos. ${ }^{9}$ Outro ponto de tensão se concentra na forma de retratação, avaliada como pejorativa, de líderes e fiéis pentecostais em algumas obras de ficção (novelas e minisséries) da Rede Globo de Televisão. ${ }^{10}$ Estes acontecimentos criaram um sentimento de perseguição em relação ao Grupo Globo, principal conglomerado de mídia do país.

Esse contexto também motivou muitas denominações a criar canais de comunicação alternativos, em alguns casos concorrentes aos veículos tradicionais. Por exemplo, a Igreja Internacional da Graça de Deus, liderada pelo Missionário R. R. Soares, criou a Rede Internacional de Televisão (RIT), de alcance nacional e com programação preponderantemente destinada ao público cristão. Em 1989, o Bispo Edir Macedo, da Igreja Universal, adquiriu a Rede Record, uma rede de televisão decadente, mas que cresceu substancialmente a partir dos anos 2000, até se tornar o segundo maior grupo de comunicação do Brasil, com base de programação para distintos grupos. Isso sem mencionar as inúmeras emissoras de rádio pertencentes às igrejas pentecostais em todo o país, registradas pelo levantamento realizado por Valdemar Figueiredo Filho. ${ }^{11}$

9 Entre estas coberturas aquelas de maior repercussão foram: 1) a prisão de Edir Macedo; 2) Em 1995 foi divulgada uma gravação de Edir Macedo, em que ele orienta os pastores sobre os preceitos da Igreja, especificamente a realização de doações financeiras pelos fiéis como modo para obter bênçãos; 3) No mesmo ano, em 1995, ocorreu o episódio conhecido como "chute na santa", faz referência ao chute dado pelo Bispo Sérgio Von Helde, da Igreja Universal, em cadeia nacional na imagem de Aparecida. Os exemplos são muitos e não restritos a um período histórico específico, mais recentemente, em 2017, o Pastor Silas Malafaia foi indiciado pela Polícia Federal para prestar esclarecimentos sobre suspeita de envolvimento em esquema de corrupção, a cobertura jornalística no caso reacendeu a hostilidade entre pentecostais e a mídia.

10 Convém lembrar o caso da minissérie "Decadência", de 1995, em que o protagonista é um pastor pentecostal, pouco ético e que enriquece por meio das doações de fiéis.

11 Muitas concessões de rádios pertencentes às igrejas foram obtidas durante o Governo do Presidente José Sarney (Partido do Movimento Democrático Brasileiro - PMDB), entre 1985 e 1990, logo em pleno processo de abertura democrática e elaboração da Constituição de 1988. As concessões de rádio e televisão, a diferentes grupos e setores, foram utilizadas em troca de apoio político para a formação de maioria parlamentar. 
A partir destes episódios muitas denominações construíram um discurso alicerçado na premissa de que pentecostais se constituíam em uma minoria religiosa, mas que poderia e deveria passar a se impor socialmente por meio da organização política, a fim de atenuar sua vulnerabilidade frente à perseguição contra sua fé, instituições e líderes. Neste sentido, de acordo com o sociólogo Leonildo Campos, frações desse segmento religioso passaram a repensar sua relação com a política e a representação institucional entre os anos de 1980 e 1990. Neste período, muitas denominações abandonaram a postura de distanciamento para com o universo político, iniciando um processo de organização para fins eleitorais.

Paulo Siepierski enfatiza a fragilidade dos/as investigadores/as em perceber este fenômeno, pois naquele momento o estudo sobre o campo religioso no Brasil se concentrou demasiadamente na atuação e relação das Comunidades Eclesiais de Base (CEBs) com os movimentos sociais e as forças políticas durante a redemocratização. Não obstante, enquanto isso estava ocorrendo transformações significativas no cenário social, político e religioso, tais como: o vertiginoso influxo de pentecostais na política institucional e nos cargos de direção dos partidos políticos.

É preciso sublinhar que entre as décadas de 1980 e de 1990 já havia no Congresso Nacional, e assembléias legislativas regionais, parlamentares ligados a algumas igrejas, porém muitos destes possuíam projeção política própria e atuavam de maneira autônoma às suas denominações religiosas, aliás, como ocorre ainda hoje. Portanto, mesmo sendo cristão e membro de uma congregação, isso não queria (quer) dizer que o parlamentar fosse incorporar e defender integralmente a agenda deste segmento religioso. Este modelo de representação, denominado por Paul Freston como autogerado, é similar a representação mediante a política de idéias, modelo hegemônico na democracia representativa, inclusive nos problemas relacionados a accountability. Isto porque, em ambos os casos, há uma autonomia dos expedientes de composição do mandato parlamentar, que em muitos casos podem estar distantes ou até mesmo em contradição com os interesses de seus eleitores e/ou de denominações religiosas. 
Sendo assim, o cenário de tensão com outros setores da sociedade agregado à incerteza de garantias dos representantes vinculados às denominações, estes elementos forneceram grandes incentivos para a construção de um modelo de representação alternativo ao autogerado. Neste mesmo período (entre os anos 1980 e 1990) houve a estruturação do modelo de representação política denominado pelo antropólogo Ari Pedro Oro de institucional, já por Paul Freston denominado de corporativo. Este modelo se define por ser uma forma de representação política que é construída no interior das igrejas, em que os mandatos são elaborados, de certa forma, para atender aos interesses das denominações (na próxima seção discutiremos a construção, estratégias e a accountability neste modelo).

O importante em pontuar agora, com base nas evidências apresentadas por Maria das Dores Machado e Joanildo Burity, é que o desejo das denominações religiosas na vida política impulsionou também o dos partidos políticos neste "mercado" de eleitores, que à época estava em franca expansão. Conforme argumenta Ari Pedro Oro, a interface entre estas instituições aprimorou o modelo institucional de representação, mediante a captação de possíveis quadros políticos no interior das igrejas, alinhados com as orientações eclesiais. Do mesmo modo, Maria das Dores Machado sustenta que a estratégia se direcionou no sentido de conscientizar os fiéis sobre a necessidade de presença da igreja na política, como forma de intervenção em temas políticos relevantes para a sobrevivência dos valores e instituições religiosas. ${ }^{12}$

Assim, o discurso sobre a necessidade de estar presente na política é construído como forma de proteção frente a um cenário adverso projetado pelas lideranças espirituais. A presença nos espaços legislativos se configuraria em instrumento de proteção de suas liberdades litúrgicas,

12 Algumas estratégias adotadas pelos pentecostais já haviam sido empreendidas pela Igreja Católica, especialmente pela Liga Eleitoral Católica na década de 1930, naquela ocasião com vistas a se consolidar politicamente frente aos grupos liberais na elaboração da Constituição de 1934. O estudo clássico de Scott Mainwaring identifica três estratégias: 1) apresentar aos seus fiéis candidaturas "aprovadas" pela instituição; 2) fomentar entre os fiéis a importância da política e; 3) recrutar no interior das igrejas possíveis quadros políticos. 
entre elas: a manutenção das práticas de cura, a libertação dos espíritos malignos e arrecadação de donativos. Logo, a preservação da liberdade religiosa é o eixo organizador do discurso para a inserção de representantes nas esferas de decisão no campo político. É possível identificar que esta justificativa se consolidou durante toda trajetória deste segmento na política brasileira, a despeito da conquista pelos pentecostais de expressivo poder de influência no campo religioso, político, econômico e midiático. ${ }^{13}$ Em determinadas circunstâncias foi mobilizada para demarcar posição frente à Igreja Católica, ${ }^{14} \mathrm{em}$ outras, para frear iniciativas em prol do respeito e de avanços na legislação, às minorias religiosas e de gênero, respectivamente (Mariano 2006; Dores Machado 2013).

Até o momento foi explicitada a construção do discurso sobre a necessidade dos pentecostais serem representados politicamente. Os principais vértices de análise demonstram os benefícios da mobilização política sob o ângulo das instituições religiosas. Pois bem, então examinamos somente uma dimensão da representação, isto é, como estas questões são elaboradas pelas lideranças religiosas e/ou políticas (em muitos casos lideranças em ambas as esferas), agora é necessário apresentar hipóteses para explicar como estes dispositivos se transformam em autorização política por parte dos fiéis/eleitores.

É possível concluir esta questão em um parágrafo, caso venhamos a assumir que estes fiéis/eleitores são irrefletidamente obedientes à hierarquia eclesial e, portanto, se posicionam politicamente de acordo com as orientações dos líderes religiosos e/ou políticos. De fato, muitos estudos, como de Simone Bohn, apontam certa homogeneidade no comportamento eleitoral destes fiéis, o que de antemão poderia validar a afirmação

13 Esta constatação está presente, por exemplo, no comportamento de suas lideranças políticas em relação aos dispositivos do código civil de 2003, analisadas por Ricardo Mariano, que tinha por intuito fixar novas regras para o funcionamento das associações religiosas no Brasil. Mesma conclusão pode ser obtida ao se examinar as falas do deputado federal Pastor Marco Feliciano (PSC-SP) e do líder religioso Silas Malafaia a respeito do projeto de lei 122/06, que visava criminalizar a homofobia, expostas em artigo de minha autoria sobre o assunto.

${ }^{14}$ As relações entre a Igreja Católica e os pentecostais têm sofrido alterações. A ascensão da Renovação Carismática no interior do catolicismo aproximou estes segmentos. 
presente na frase anterior. Entretanto, nossa preocupação consiste em apresentar hipóteses para as razões deste comportamento, ou seja, discutir como são formadas as preferências e as identidades políticas neste ambiente.

Para discorrer sobre o assunto, o ponto de partida são as contribuições da cientista política Iris Young, nomeadamente a noção de grupo e das perspectivas sociais como elementos definidores do caráter constitutivo da representação política. A autora define os grupos sociais como portadores de demandas e identidades compartilhadas, ao invés de compreendê-los segundo vínculos associativos ou atributos objetivos, tais como: cor da pele ou sexo. Ao romper com esta lógica substancial Iris Young abandona pressupostos essencialistas e assume a visão de que os indivíduos devem ser compreendidos por suas posições nas estruturas dos grupos sociais, sem que isso seja determinante para suas identidades. Dessa forma, os indivíduos possuem múltiplas posições de sujeito, por isso não há uma identidade unívoca capaz de reorganizar os interesses coletivos e construir a representação política.

De fato, a fé pode ser um componente central para as pessoas devotas, porém esta crença e o vínculo associativo a uma instituição religiosa se constituem em apenas um aspecto, entre muitos, da vida destes fiéis. Esta constatação pode ser maximizada se considerarmos algumas denominações pentecostais relevantes no Brasil, haja vista que a adoção da teologia da prosperidade se converteu em singularidade litúrgica de parcela do segmento em relação às demais religiões de matriz cristã. Esta perspectiva teológica advoga e estimula que os cristãos devem buscar alcançar êxito financeiro através de suas atividades profissionais e/ou pelo empreendedorismo individual, baseado na premissa de que a espiritualidade não é somente um bem interior, mas ela se reflete nas condições de vida de quem crê em deus. ${ }^{15}$

15 Um exemplo disso são os testemunhos em cultos nas igrejas, alguns transmitidos pela televisão, em que o relato das pessoas frequentemente aponta para a superação de condições adversas para a conquista da prosperidade financeira. Além de relatar sobre o êxito profissional, apresentar seus imóveis e automóveis, os testemunhos salientam que a prosperidade é fruto da comunhão com deus e do esforço individual. 
Portanto, o pertencimento religioso e os interesses políticos da igreja são insuficientes para condicionar as preferências políticas destes fiéis. Neste contexto, é plausível refletir que estes devotos pentecostais desenvolvem interesses econômicos e sociais específicos, que podem ser muito distintos daqueles enunciados pela direção eclesial. Desse modo, embora muitos fiéis sejam obedientes às orientações religiosas de seus líderes, no tocante aos "passos a seguir para encontrar deus", no entanto este aspecto não poder ser automaticamente convertido para explicar integralmente o processo de autorização política neste espaço.

Por estas razões, estamos mais inclinados a entender que este grupo engendra a fé, e seus valores intrínsecos, como perspectiva social entre os membros de uma congregação. O posicionamento similar no campo social permite a estes fiéis um ponto de vista particular sobre as dinâmicas sociais e a autorização política, visto que a noção de perspectiva social compreende que "as experiências culturais de povos ou de grupos religiosos diferenciados, frequentemente lhes conferem interpretações refinadas acerca de suas próprias situações e de suas relações com outros grupos" (Young 2000: 137).

Esta concepção é útil para explicar a formação das preferências políticas destes fiéis em torno das candidaturas apresentadas por suas denominações, já que os estudos de caso sobre o comportamento eleitoral e a identidade política dos pentecostais, sobretudo os de Simone Bohn e também de Pedro Geraldo, demonstram a enunciação de uma identidade coletiva que visa diferenciá-los dos demais grupos sociais. A partir disso, há a construção de demandas e de visões de mundo compartilhadas entre os fiéis, que serão representadas politicamente por um bispo, pastor, colaborador ou membro da denominação.

As igrejas têm grande capacidade de transformar o pertencimento religioso em um mecanismo de autorização política, De acordo com Simone Bohn, este fato pode ser constatado no Brasil e em outros países, como os Estados Unidos e a Inglaterra. No caso brasileiro, Ari Pedro Oro (2003a) destaca que isto ocorre mediante o translado para o campo político de importantes elementos simbólicos e práticos do campo religioso. 
Este "sincretismo" entre duas esferas distintas promove a percepção de que os representantes são extensões na política dos mesmos princípios aos quais os fiéis são devotos.

Há pelo menos três pilares que compõem esta perspectiva social e que definem este translado de valores religiosos convertidos em plataforma política. O primeiro deles é o proselitismo religioso, presente na "missão de salvar" aqueles que estão perdidos dos "caminhos de deus". Leonildo Campos e Maria das Dores Machado assinalam que a singularidade no discurso dos representantes pentecostais na vida política brasileira repousa sob o argumento de sua atuação messiânica, ou seja, a elocução de que são portadores de uma moralidade capaz de restaurar a ética na política.

Esta lógica emerge como contraposição ao consenso social de que os representantes políticos são corruptos e preocupados somente com seus interesses. Sendo assim, os chamados "políticos de cristo" se apresentam como homens e mulheres de reputação e conduta ilibadas, idôneas e incorruptíveis, isto é, emissários de um perfil idealizado pela opinião pública e a antítese ao panorama vigente no Congresso Nacional e nas assembleias legislativas regionais.

Estes pontos são salientados pelo Bispo Rodrigues ${ }^{16}$ da Igreja Universal, como o diferencial destes representantes em relação aos demais: "Em meio a tantas falcatruas e espertezas que vigoram na política do país, os homens e mulheres que levam o nome de Deus não se deixaram contaminar pela prática comum da corrupção. Os nossos candidatos mostraram, na prática, o que é verdadeiramente a ética na política" (Oro 2003: 104). ${ }^{17}$

16 Em 2005, o Bispo Rodrigues foi denunciado pelo envolvimento no Escândalo do "Mensalão" (sistema de corrupção no Congresso Nacional baseado na compra de votos para formação de maioria parlamentar) e, em 2006, no Escândalo dos Sanguessugas (relacionado a corrupção e desvio de verbas destinadas a comprar ambulâncias), tendo renunciado ao cargo em 2005 e sido preso por determinação do STF em 2013.

17 Em outras passagens, o bispo/parlamentar relata que: "Os espíritos que atuam na política são os espíritos dominadores, os príncipes das Trevas". "O diabo está alojado dentro do Congresso Nacional, criando lei injustas e erradas". "A maioria dos políticos estão a serviço do satanás" (Oro 2003: 58). 
Conforme sustenta Leonildo Campos, o propósito deste segmento no campo político seria a "purificação" deste espaço, ou melhor, a conquista para o "reino de Deus" das esferas que estão sob "domínio do Diabo". A "guerra espiritual" contra as forças ocultas é elemento simbólico relevante na construção litúrgica de muitas destas denominações. Todavia, passou também a ser peça central na convocação para participação política dos fiéis, com vistas a unir forças para "libertar" e retirar o Congresso Nacional das "mãos de Satanás".

O segundo pilar consiste na defesa da família tradicional heteronormativa. Esta premissa está relacionada aos valores religiosos e também ao chamado discurso messiânico, uma vez que seu propósito é impedir a subversão de princípios morais. Um dos traços distintivos do modus operandi destes representantes, conforme destaca Maria das Dores Machado, é justamente se apresentar como reserva moral dos valores tradicionais, sobretudo por meio da resistência à reconfiguração das noções de família e casamento. O último pilar se configura pela promessa religiosa que se transporta para os programas dos representantes políticos, a saber, pela crença no evangelho elevar a prosperidade e o bem-estar social no Brasil (Filho 2002).

Somando estes pontos eles nos permitem refletir que o processo de autorização política dos fiéis às candidaturas apresentadas por suas denominações, em realidade, são desdobramentos de uma perspectiva social partilhada por este grupo, e que estão presentes nas plataformas destes representantes políticos. Para corroborar esta constatação, vale salientar os dados aferidos pela pesquisa de Maria das Dores Machado e Joanildo Burity, em que as "boas ideias políticas" dos candidatos aparecem como fator principal da definição dos votos dos fiéis, inclusive à frente da identidade religiosa.

Assim, não nos parece razoável supor que o processo de autorização política destes fiéis/eleitores seja somente reflexo da obediência às orientações de seus líderes religiosos. Por um lado, é preciso considerar que as motivações das instituições religiosas na política (discutidos anteriormente) sensibilizam alguns fiéis/eleitores. Apesar disso, há de se considerar 
também a perspectiva social como indicador importante na explicação da adesão dos fiéis/eleitores às candidaturas e aos representantes de suas denominações, mesmo que esta perspectiva social, em alguns pontos, seja problemática do ponto de vista democrático (este ponto de discussão será tratado mais adiante).

\section{A CONSTRUÇÃO DO MODELO INSTITUCIONAL}

E OS PERIGOS À DEMOCRACIA BRASILEIRA

Ao longo da seção anterior deixamos dois pontos para serem tratados neste momento. Em primeiro lugar, analisar como o modelo institucional ou corporativo foi construído, destarte, verificar como a relação entre representante e representado funciona neste modelo. Em segundo lugar, esclarecer porque esta forma de representação pode ser considerada perigosa à democracia brasileira.

O cenário de conflito entre a década de 1980 e 1990 promoveu mudanças na forma da representação política dos pentecostais, mediante a estruturação de um modelo alternativo ao autogerado, isto é, quando o/a parlamentar professa a crença religiosa e em algumas situações pode ou não defendê-la em seu mandato, já que sua carreira política é, em boa medida, resultado de sua própria trajetória. ${ }^{18}$ Para ilustrar essa transformação dos representantes associados às denominações pentecostais, Leonildo Campos constrói uma tipologia para melhor definir esta mudança. Entende o autor que os parlamentares anteriores à Constituição de 1988 atuavam de modo fragmentado, aos quais ele denomina de "políticos evangélicos". Já os chamados "políticos de Cristo", amadureceram suas

18 A investigação de Fábio Lacerda aponta que esta fórmula de representação é predominante entre as igrejas protestantes, portanto, não há a construção de "candidatos oficiais". Na composição da "bancada evangélica" há muitos parlamentares membros, por exemplo, da Igreja Batista, Presbiteriana e Metodista, mas na maior parte dos casos é inexistente o estreito vínculo de compromisso dos parlamentares com as denominações. 
estratégias no panorama político pré e pós-1988 e, por sua vez, esboçam grande capacidade de atuação conjunta, sobretudo em discussões de interferência nos valores morais, como os direitos à cidadania LGBTTQ e os direitos sexuais e reprodutivos das mulheres.

A reprodução por outras denominações de práticas político-eleitorais exercidas pela Igreja Universal é entendida como uma das principais variáveis para a expansão do modelo institucional ou corporativo. A Igreja Universal (IURD) foi a instituição que empreendeu de forma mais ostensiva (desde os anos 1980) a estratégia de ocupação dos espaços políticos, majoritariamente nas casas legislativas. Os motivos para esta mobilização já foram examinados, isto é, o temor de forças sociais e políticas adversas aos pentecostais. Contudo, a organização com objetivos políticos na IURD não se restringiu a influenciar os contornos da Constituição de 1988, pelo contrário, foi ampliado nas eleições subseqüentes por meio da estruturação de táticas articuladas por lideranças remanescentes de seu alto escalão, tais como: Bispo Rodrigues e o Bispo Marcelo Crivella, figuras centrais na fundação desta denominação.

Entre estas estratégias, duas parecem ser fundamentais na consolidação do modelo institucional. A primeira delas se refere ao engajamento de bispos, pastores e colaboradores nos períodos eleitorais em favor dos candidatos promovidos pela Igreja Universal. Isto mediante atividades de apresentação dos candidatos em cultos, exposição de cartazes, pregações sobre a importância de eleger cristãos até a mobilização dos instrumentos mais convencionais, como a distribuição de "santinhos" (papéis impressos com a foto, cargo e outras informações do candidato), aos fiéis e a população em geral.

A segunda estratégia, talvez a mais importante, seja o que caracterize com mais propriedade esta forma de representação, a saber, o carisma institucional. Este dispositivo, com base nas considerações de Ari Pedro Oro e Paul Freston, constrói mecanismos de vinculação do mandato com a instituição, o que significa dizer que as candidaturas são construídas no interior da igreja e para atender os desígnios dela, sendo irrelevante o capital político do candidato (em grande parte das vezes ele nem existe). 
É necessário apresentar exemplos ilustrar com mais propriedade o carisma institucional. No primeiro caso, as investigações de Ari Pedro Oro, Maria das Dores Machado e Ricardo Mariano constatam que muitos parlamentares eram oriundos e construíram suas vidas em uma determinada região do Brasil, não obstante, foram "enviados" para pregar e/ou se candidatar a cargo político por outra região. Dessa forma, em boa parte dos casos não há relação direta entre o candidato e o fiel/eleitor, muito menos com suas demandas locais, salvo a certeza de que determinadas perspectivas sociais serão defendidas no âmbito legislativo.

Vale destacar que as candidaturas oficiais da Igreja Universal são promovidas a partir de um "recenseamento" prévio, realizado para identificar as características de seus fiéis em determinado distrito eleitoral, cujo intuito é definir o perfil do candidato e do programa a ser apresentado (identificadas por Ari Pedro Oro, 2003a). Estes dados são também analisados pela direção para verificar a plausibilidade da candidatura, com vistas a diagnosticar quantos candidatos a instituição deverá promover. Com base nisso, as candidaturas apresentadas atendem a um perfil passível de adesão, apesar de serem desconhecidos de seus futuros eleitores. Esta estratégia conflui com nossa hipótese, que entende o processo de autorização política destes fiéis a partir de uma perspectiva social (que não é somente a fé), presente nas ações e nas plataformas eleitorais dos candidatos.

Por outro lado, o segundo exemplo consiste na impactante derrota de candidatos que anteriormente eram apoiados pela IURD, mas que resolveram se candidatar espontaneamente nas eleições seguintes. Estes exemplos reforçam as conclusões a respeito da estruturação de uma série de dispositivos que faz com que o mandato, até certo ponto, "pertença" a denominação religiosa, em detrimento do candidato e do partido político. Esta situação é inteiramente diferente do modelo autogerado, identificado na representação de setores da Igreja Católica e denominações protestantes históricas, pois neste caso há definições prévias de como se posicionar e a quem prestar contas, caso o desejo seja a manutenção da carreira política.

O êxito eleitoral destas estratégias promoveu durante os anos 1990 um debate entre as denominações, a respeito da necessidade de seguir o 
modelo adotado pela IURD (Machado 2012). Alguns líderes religiosos (entre eles, o Pastor Silas Malafaia) chegaram a expressar que esta forma de se organizar politicamente deveria ser reproduzida pelas demais forças do campo religioso, com vistas a ampliar o poder de influência destas igrejas, bem como obter representação de suas demandas no âmbito político.

Apesar de certo consenso em relação à necessidade de construir estratégias políticas, é preciso avaliar que boa parte das igrejas se mantém com uma base organizacional diferente da estrutura da IURD, que de acordo com Ricardo Mariano se caracteriza por ser extremamente centralizada e verticalizada. A estrutura organizacional nestes moldes é fundamental, na visão de Ari Pedro Oro, para a execução e o êxito deste modelo de representação política. Por isso, a diversidade organizacional das denominações pentecostais impõe diferenças no modo de articulação no campo político. A Assembleia de Deus, por exemplo, é bem mais heterogênea, pois é composta por ministérios regionais parcialmente autônomos em relação à liderança central, e alguns totalmente independentes. Este elemento é muito importante à medida que permite entender as razões de alguns setores da Assembleia de Deus reproduzirem o modelo institucional da IURD, ao passo que outros não, inclusive preservando uma postura apolítica. Diferentemente, a Igreja do Evangelho Quadrangular reproduziu o modelo da IURD, porém com diferenças interessantes, tais como a realização de prévias internas para a escolha dos candidatos oficiais.

Neste período houve maior regulamentação da legislação eleitoral, que passou a prever os casos de atuação política das religiões. A Lei federal nº 9.504 de 1997 (artigo 24, inciso VIII), chamada Lei das Eleições, estabeleceu como crime eleitoral o recebimento direto ou indireto de favorecimentos aos candidatos, via doações em dinheiro ou por meio de publicidade de qualquer espécie, procedentes de entidades de natureza pública, entre elas, beneficentes e religiosas. A Lei federal 11.330 de 2006, ratificou estes dispositivos e, além disso, determinou regras mais rígidas para as doações, propagandas e prestação de contas das campanhas eleitorais. Apesar da introdução de normas para regulamentar a atividade política de entidades de natureza pública, o processo de fiscalização 
para coibir situações de abuso do poder religioso sobre as preferências eleitorais dos/as fiéis tem sido geralmente ineficaz. Há escassas ocorrências de enquadramento das religiões a estas normas, em virtude da difícil operacionalização de controle a todas as entidades (além das igrejas) e também por ser um tema juridicamente complexo, devido a sua relação com a liberdade religiosa. Mesmo assim a ação de muitas denominações nos anos 2000 se direcionou no sentido de evitar a associação de forma tácita de seus candidatos à imagem da igreja.

Como é possível verificar no gráfico abaixo, a adoção destas estratégias resultou no crescimento paulatino da chamada "bancada evangélica" durante os anos 1990. Esta constatação conflui com a perspectiva de que somente entre os anos 1990 e 2000 estas estratégias de articulação política foram incorporadas por um número maior de denominações. Para alguns analistas, como Maria das Dores Machado, é neste período que será possível verificar com mais clareza a composição de um arranjo minimamente regular, e a construção de um discurso mais unívoco, que possa caracterizar a agenda dos parlamentares da "bancada evangélica".

Gráfico 1: Apresenta a quantidade de Deputados Federais vinculados a "Bancada Evangélica", em cada legislatura a partir de 1982 até 2018. ${ }^{19}$

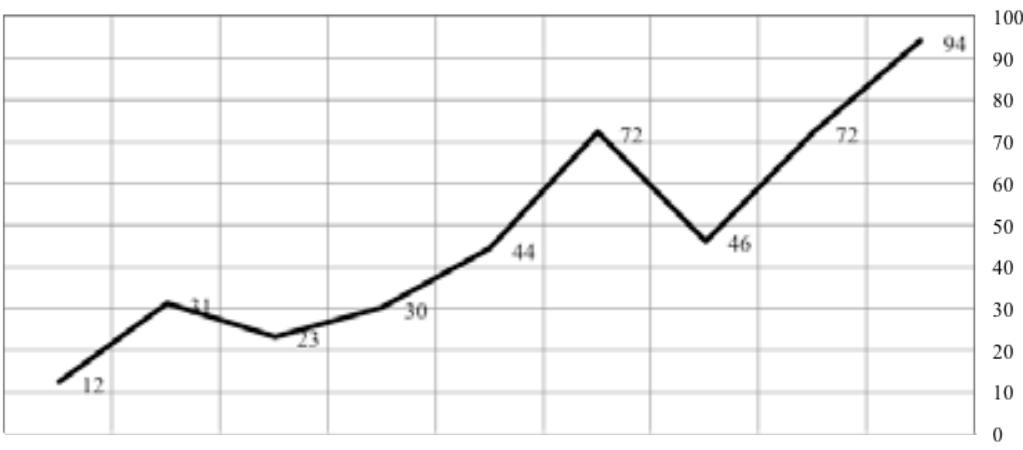

$\begin{array}{lllllllll}1982-1985 & 1986-1990 & 1991-1994 & 1995-1998 & 1999-2002 & 2003-2006 & 2007-2010 & 2011-2014 & 2015-2018\end{array}$

Fonte: Elaboração Própria, com base em Leonildo Campos; Maria das Dores Machado; FPE (2018).

19 Na composição da bancada evangélica,o número de deputados vinculados as igrejas protestantes representa em torno de 10 a 20 parlamentares por legislatura. 
A única diminuição registrada na "bancada evangélica" pós-redemocratização ocorreu nas eleições de 2006, quando a referida bancada perdeu quase metade de seus representantes. Este fenômeno está correlacionado com as denúncias sobre o sistema de corrupção vigente no Congresso Nacional, denominado "Mensalão", tornado público no ano de 2005. Entre os envolvidos destacam-se a presença de 28 dos 72 deputados federais da "bancada evangélica", principalmente os representantes das Igrejas: Universal e Assembleia de Deus. Conforme sustenta Maria das Dores Machado (2013), este acontecimento provocou o recuo no discurso de restauração da ética na política, desde então, segundo a autora, há maior ênfase em outros aspectos, como a defesa do ideário da família tradicional.

Nas eleições subseqüentes, realizadas em 2010 e 2014, este segmento recuperou toda sua força numérica e política no Poder Legislativo federal. Atualmente, a "bancada evangélica" é composta por 18,3\% (94) do total de 513 parlamentares da Câmara dos Deputados, e 4\% (3) do total de 81 Senadores. ${ }^{20}$

O mais interessante é notar que estes parlamentares estão dispersos em 19 partidos. ${ }^{21}$ Fato interessante, haja vista que o Partido da República (PR) e o Partido Republicano Brasileiro (PRB) são "vinculados" à Igreja Universal, ${ }^{22}$ já o Partido Social Cristão (PSC) à Assembleia de Deus. Todavia, isso não foi suficiente para que grande parte dos parlamentares associados às diferentes denominações se candidatasse exclusivamente por estes partidos.

A pulverização dos pentecostais no sistema partidário brasileiro é uma questão que mobiliza a atenção dos/as analistas desde o início da

20 De acordo com o Censo de 2010, realizado pelo Instituto Brasileiro de Geografia e Estatística (IBGE), os evangélicos correspondem a 22,2\% (de 200 milhões) da população brasileira.

21 PR, PTB, PRTB, PMDB, PSC, PT, PSDB, PDT, PSL, DEM, PP, PV, PSB, PRB, PROS, SD, PTN, PPS, PSD.

22 O Partido da República foi fundado em 2006, sendo remanescente do Partido Liberal (PL). O escândalo do "mensalão" provocou o desgaste da sigla, assim como de suas principais lideranças, como o Bispo Rodrigues. O Partido Republicano Brasileiro foi fundado em 2005, portanto, também neste contexto de denúncias e investigações sobre o caso de corrupção. 
imersão deste segmento na vida política, destaco aqui as investigações de Tiago Borges Daher e Simone Bohn. Isto porque, esta forma de atuação diverge imensamente da adotada pelas religiões em países europeus e asiáticos desde a metade do século XX, pois a mobilização é realizada via criação de partidos confessionais, em alguns casos a ponto de dividir o sistema partidário (em partidos seculares e confessionais). É bem verdade que o objetivo destes partidos confessionais na Europa e na Ásia se concentra em recuperar privilégios perdidos ao longo do processo de secularização de alguns países, conforme já discutido, este não é o caso dos pentecostais no Brasil.

Há o diagnóstico de dois caminhos para analisar esta questão. O primeiro deles, representados pelos resultados das investigações de Regina Novaes e Alexandre Fonseca, apontam para inexistência de uma identidade entre os representantes das variadas denominações que compõem a chamada "bancada evangélica". Isto em função de haver poucos temas em que há coesão entre este grupo. De acordo com o que já foi dito, as denominações e seus representantes formam um grupo social heterogêneo, o que reflete em divergências de posições entre estes parlamentares. Há algumas exceções neste comportamento, as quais unificam a agenda destes representantes, entre estas, a oposição às intenções legislativas de reconfigurar os valores morais.

O segundo caminho, também presente nas investigações das investigações supracitadas e por considerações de Maria das Dores Machado, Ricardo Mariano e Ari Pedro Oro, apontam que a pulverização é também resultado do conhecimento de líderes políticos e/ou religiosos sobre o sistema político brasileiro. Sendo assim, esse fenômeno é percebido como uma estratégia, ao invés de fragmentação entre os representantes políticos vinculados à "bancada evangélica". Visto que a pulverização desses parlamentares permite alcançar, em alguns temas, maior poder de barganha para influenciar o sistema partidário como um todo, desde as lideranças até os parlamentares do mesmo partido político. Além disso, a ausência de concentração em um ou mais partido(s) de caráter confessional cumpre a função de desvincular a imagem destes representantes 
como somente porta-vozes do campo religioso. Em certos casos a estratégia resulta em benefícios, na medida em que permite a ampliação do espectro de eleitores.

Este recurso é uma das características mais singulares identificadas por Pedro Geraldo na campanha política do então Senador Marcelo Crivella para a prefeitura do Rio de Janeiro em 2004, por exemplo, houve enorme esforço para desvincular sua imagem da relevante posição que ocupa na hierarquia da Igreja Universal. Esta estratégia se consolidou em outras eleições de Marcelo Crivella para o Poder Executivo no Rio de Janeiro, especificamente nas eleições de 2006 e 2014 para o governo do Estado (regional/província), ${ }^{23}$ e em 2016 quando se elegeu prefeito da referida cidade.

Estas formas de compreensão não são excludentes, mas complementares, por esboçar preocupações no plano de estudo sobre este segmento no Brasil. A primeira tem como aporte identificar o modo de atuação dos parlamentares desta "bancada" e os eixos temáticos de alinhamento em algumas agendas, embora estejam em campos opostos em outras. Já a segunda apresenta a utilização deste mecanismo como estratégia política e eleitoral.

Por um lado, é possível notar estímulos desfavoráveis para este setor em concentrar toda sua força em apenas um partido político confessional. Para além das diferenças e disputas litúrgicas e políticas entre os pentecostais, há de se ponderar os custos e a imprevisibilidade desta ação na influência do sistema político partidário, o que torna a construção de partidos e candidaturas com característica puramente confessional inviável e estrategicamente pouco vantajosa. Por outro, isso não significa que os partidos políticos de caráter confessional supracitados sejam enfraquecidos, em virtude do processo de pulverização dos representantes nas demais agremiações partidárias.

Neste texto queremos apresentar uma hipótese de investigação inexplorada, ainda em fase de construção das evidências, sobre o conheci-

23 O mandato dos senadores no Brasil tem duração de oito anos, assim é possível concorrer a outros cargos políticos e, em caso de derrota, preservar-se como senador. Marcelo Crivella foi eleito senador em 2002 (pelo Partido Liberal - PL) e 2010 (pelo Partido Republicano do Brasileiro - PRB) pelo Rio de Janeiro. 
mento e uso das regras eleitorais pelas lideranças políticas e/ou religiosas das igrejas pentecostais, com a finalidade de eleger seus representantes e fortalecer os partidos confessionais. Essa hipótese se concentra na investigação da utilização de candidatos com prestígio entre a população, em virtude de sua visibilidade nos meios de comunicação, para conquistar votos a um partido ou coligação, conhecido como "puxadores de voto". ${ }^{24}$ A hipótese se sustenta a partir de situações ocorridas em São Paulo nas eleições de 2010 e 2014, quando o Partido da República (PR) e o Partido Republicano Brasileiro (PRB), ligados à Igreja Universal, promoveram candidatos como: Tiririca (PR), Celso Russomano (PRB) e Sérgio Reis (PRB). ${ }^{25}$

Na eleição de 2010, o candidato Tiririca (PR-SP) foi eleito deputado federal com mais de 1350000 de votos, o suficiente para ultrapassar quatro vezes o quociente eleitoral, por conseguinte, garantir sua vaga e eleger outros três candidatos de sua coligação. ${ }^{26} \mathrm{Na}$ eleição de 2014 o fenômeno se repetiu, Tiririca (PR-SP) reelegeu-se e garantiu outros dois candidatos, desta vez apenas do PR, já que não houve coligação a outros partidos nesta eleição. Por sua vez, Celso Russomano (PRB-SP) foi eleito deputado federal com mais de 1500000 de votos nas eleições de 2014, garantindo sua vaga

24 O Brasil adota nas eleições legislativa o sistema proporcional de lista aberta com possibilidade de coligações entre os partidos. Os partidos ou coligações (união entre partidos no período eleitoral, cujo resultado é maior competitividade devido à unificação da contabilização dos votos) obtêm cargos políticos na medida em que é atingido um número mínimo de votos, o quociente eleitoral. Por exemplo, caso o partido ou coligação X alcance votação equivalente a duas vezes o quociente eleitoral, isso significa que o partido ou coligação obterá dois cargos no legislativo. Nesta situação, os candidatos mais votados são eleitos, independentemente se esta votação é alta no contexto geral da eleição, pois os cargos são conquistados não pela votação individual do candidato, mas pela quantidade de votos recebida pelo partido ou coligação (ver o estudo clássico de Jairo Nicolau).

25 Celso Russomano é apresentador de televisão da Rede Record (como já dito pertence à Igreja Universal), conquistou notoriedade nacional pela defesa dos direitos do consumidor e por denúncias às empresas que violam tais direitos. Sérgio Reis é conhecido canto da música popular brasileira, do gênero sertanejo. Tiririca (Francisco Silva) é ator e cantor, conhecido por sua atuação como humorista, também trabalha na Rede Record.

26 A votação expressiva não beneficiou nenhum candidato do PR, as vagas foram conquistas por candidatos de outros partidos de sua coligação. 
e elegendo outros quatro candidatos do PRB, que também não se coligou a outros partidos.

Há três aspectos em comum entre os casos..$^{27}$ Primeiramente, boa parte dos demais candidatos beneficiados obteve índices de votação ínfimos para um distrito eleitoral como São Paulo, entre 25 e 50 mil votos. Por outro lado, a maioria dos beneficiados exercia funções eclesiásticas ou possuía ligação com as igrejas pentecostais, sobretudo a Universal, entre eles: o Pastor Roberto Alves (PRB), Bispo Antonio Bulhões (PRB), Fausto Pinato (PRB), Vinicius Carvalho (PRB) e Paulo Freire (PR). Por último, a ausência de coligações é um indicador de estratégia, especialmente em distritos eleitorais grandes como São Paulo, pois há risco enorme de ninguém se eleger, mas em caso êxito apenas os candidatos do partido são beneficiados.

Esta estratégia eleitoral, chamada de "efeito carona", é praticada por muitos partidos políticos no Brasil, mas os resultados são incertos e poucas vezes tão exitosos. Por exemplo, o candidato Sérgio Reis (PRB-SP), embora mais reconhecido que os outros dois em razão de sua longa trajetória artística, obteve apenas 45 mil votos, sendo eleito deputado federal por conta da votação de Celso Russomano (PRB-SP). Convém ressaltar novamente, que esta é apenas uma hipótese de investigação sobre a circunstância de formação destas candidaturas, que requer novas evidências a partir das eleições de 2018.

Sendo assim, a reprodução das práticas político-eleitorais construídas pela Igreja Universal é uma das principais variáveis para compreender a forma de representação política adotada (com variações) por boa parte dos pentecostais. ${ }^{28}$ Conforme já dito, há momentos definidores a respeito da necessidade de planejamento deste molde de representação, os passos em direção a um arquétipo balizador de representação são gradativos, no

27 Celso Russomano (PRB-SP) e Tiririca (PR-SP) ocupam a $2^{\circ}$ e $3^{\circ}$ posição, respectivamente, entre os deputados federais mais votados da história do Brasil.

28 Este sistema integrado de estratégias políticas promoveu impacto significativo no campo religioso, influenciado setores da Igreja Católica e lideranças das religiões afro-brasileiras (Oro 2003). 
que tange a incorporação desta articulação política por um número maior de denominações pentecostais.

À primeira vista poderíamos pensar que o modelo institucional de representação subverte o diagnóstico corrente das análises políticas, sobre a crescente ausência de responsividade e de prestação de contas na relação entre representantes e representados. Este tema se tornou nas últimas décadas preocupação de primeira importância nos debates sobre o funcionamento das democracias ocidentais, no Brasil refletidas nas investigações do cientista político Luis Felipe Miguel. Algumas alternativas são alçadas no sentido de diminuir a distância entre representante e representado. No Brasil, por exemplo, a reforma política e suas várias propostas visam atenuar este problema. Entretanto, segundo Luis Felipe Miguel, é consenso a necessidade de construir canais sociais e institucionais para instituir maior diálogo e/ou sanções efetivas aos representantes, com o objetivo de vincular o parlamentar às perspectivas e aos grupos que representa.

Como visto até aqui, o modelo institucional elimina a possibilidade de autonomização do mandato, uma vez que a projeção política e as candidaturas dependem da prestação de contas à denominação religiosa que oferece apoio ao candidato, assim como os recursos e eleitorado com potencial possibilidade de adesão. Isto de nenhum modo quer dizer que seu mandato é imperativo, ou seja, que o/a parlamentar expresse somente a vontade de sua base, até porque há grande variedade de assuntos em que estes parlamentares estão envolvidos. Esta questão apenas salienta que há sanções efetivas que podem ser aplicadas pelas direções das igrejas aos parlamentares "desalinhados" com a representação das perspectivas sociais da comunidade religiosa.

Se entendermos que os interesses das lideranças das igrejas são os mesmos de seus eleitores/fiéis, a prestação de contas é realizada com êxito, poisa cúpula eclesial analisa o mandato do parlamentar e realiza um balanço sobre a possibilidade de conferir nova oportunidade ou promover outra candidatura. A partir disso, delega aos eleitores/fiéis apenas a função de outorgar sua autorização política. Podemos presumir que existe uma 
similaridade entre os projetos e as preferências nestas esferas, que envolvem igreja, representantes e os eleitores/fiéis. Sendo assim, conforme salienta Luis Felipe Miguel, a similitude complementa a accountability, pois as perspectivas sociais do grupo serão analisadas (pelo candidato e pela igreja) e respeitadas. Neste cenário, cabe ao parlamentar seguir as principais diretrizes da igreja que, por sua vez, é em tese "portadora" da "vontade coletiva" de seus fiéis. Nossa digressão está na contramão desta assertiva.

A questão é complexa e reflete diversos posicionamentos sobre o funcionamento da accountability. Por exemplo, estejamos propensos a entender que a accountability vertical ${ }^{29}$ é o suficiente para a vitalidade do regime democrático, onde a informação e interlocução entre representante e representado são mínimas, então há pouco a se pensar sobre o fenômeno. No entanto, se consideramos que este mecanismo deve ser utilizado para aprimorar a compreensão dos eleitores sobre temas de seu interesse, elevar a educação política dos eleitores e, por conseguinte, conferir maior legitimidade ao mandato através da interlocução, então há boas razões para problematizar a questão.

Estamos mais inclinados à segunda perspectiva, porém sabemos que há dificuldades estruturais que tornam o processo de accountability moroso e com altos custos para sua operacionalização. Em primeiro lugar, há de se considerar que a disponibilização de todas as informações do mandato aos eleitores gera custos significativos, por exemplo, encargos financeiros, recursos humanos e tempo. Esta questão é acentuada devido à multifuncionalidade da representação em um país de proporções continentais, profundamente heterogêneo e complexo, cujo envolvimento parlamentar abrange diversas agendas políticas.

Diferentemente da maioria dos/as parlamentares que compõem o Congresso Nacional, os representantes pentecostais dispõem de uma situação mais favorável no que tange à possibilidade de criar canais de comunicação sólidos com seus eleitores e corrigir as dificuldades que impõem limites a accountability. Tendo em vista que grande parte de

29 Exercida por representantes políticos em boa parte das democracias representativas. 
seu eleitorado está parcialmente definido, pois se reúne com certa periodicidade em cultos de suas denominações, as quais, em boa parte dos casos, os/as representantes também são membros. Este fator delimita o raio de ação do gabinete parlamentar, ao mesmo tempo em que facilita a elaboração de discussões, prestação de contas e de informações sobre os desafios da atividade legislativa. Além disso, é preciso ponderar que boa parte das denominações pentecostais possui veículos de comunicação, o que proporciona aos representantes políticos amplo suporte para difusão de idéias, organização de atividades e informação sobre fenômenos políticos à sua base eleitoral.

Diante destas constatações, é plausível aferir que os eleitores/fiéis dispõem de mecanismos muito semelhantes aos dos eleitores comuns, posto que embora haja similaridade entre as perspectivas sociais defendidas no mandato parlamentar com as dos eleitores/fiéis, com isso prescindindo de formas mais efetivas de accountability. No entanto, precisamos ponderar a existência da igreja (instituição) no meio deste processo. Esse fator, segundo Paul Freston, cria um ruído na relação entre representante e representado, já que os interesses da igreja tendem a prevalecer em relação aos do eleitorado/congregação.

Neste panorama, Paul Freston assinala que os eleitores/fiéis não são convocados para formular a construção das vontades coletivas e das perspectivas sociais vigentes no mandato, cabe a eles somente o papel de fiscalizar as ações dos representantes. Do mesmo modo, o único mecanismo de sanção efetiva desta base eleitoral é a autorização política ou a ausência dela às candidaturas apresentadas por suas denominações, porquanto que as sanções efetivas são realizadas pelas direções das igrejas, que disponibilizam candidaturas já constituídas. Dessa forma, os eleitores/fiéis não se constituem como partícipes ativos da elaboração das candidaturas, o que neste ambiente delimitado seria razoável e até de simples execução. ${ }^{30}$ So-

30 Há de se destacar o caso da Igreja do Evangelho Quadrangular, que realiza prévias internas para a escolha dos candidatos, entretanto, esta iniciativa é isolada e não apresentou impacto no campo religioso. Precisamos refletir que esta situação (embora seja um enorme avanço em relação a outras denominações), apenas confere aos fiéis 
madas estas circunstâncias, nota-se que os mecanismos à disposição destes eleitores/fiéis são modestos, para não dizer muito similares aos disponíveis aos demais cidadãos que não estão engajados em um grupo social.

Por mais que a hierarquia eclesial e seus interesses não sejam elementos suficientes para garantir a autorização política desta base eleitoral (pois, há perspectivas sociais envolvidas), é notório seu protagonismo na organização dos arranjos políticos presentes neste segmento. Pensando nos problemas que os modelos autogerado e institucional engendram para os eleitores/fiéis, especialmente na construção de formas de sanções mais efetivas e dos canais de accountability, Paul Freston entende que o modelo comunitário poderia corrigir as distorções identificadas nas outras duas formas de representação. De acordo com a proposta apresentada sua proposta, esse modelo deveria se desenvolver mediante o envolvimento político dos fiéis, não em nome de suas igrejas, mas por demandas articuladas e debatidas pelos fiéis no interior de suas denominações, com o propósito também de deliberar sobre o apoio aos/as postulantes à representação.

A partir disso, os parlamentares não exerceriam seus mandatos de forma autônoma (modelo autogerado), e muito menos estariam somente submetidos à hierarquia eclesial (modelo institucional). Neste contexto, os representantes estariam em permanente interação com sua base. Paul Freston (2006) não considera este modelo isento de problemas, especialmente operacionais, não obstante pondera que entre os três modelos este possibilita ao eleitor/fiel maior poder de decisão.

O modelo institucional tem sido efetivo no processo de representação política dos interesses das denominações no âmbito legislativo, assim como por conjugar componentes da perspectiva social dos membros das congregações, no entanto é necessário avaliar os riscos de sua execução e ascensão à democracia brasileira. Isto dito, tendo em vista que os princípios e as demandas que alicerçam esta representação se caracterizam por seus aspectos corporativos, ou seja, a primazia da proteção

a decisão sobre um contingente maior de postulantes (já previamente escolhidos) a candidato oficial. 
dos interesses e valores morais de sustentação das igrejas pentecostais, os quais são colocados "acima" da política, dos programas partidários e da pluralidade social e religiosa existente no Brasil. Os dados de nossa investigação demonstram que os representantes políticos da "bancada evangélica" se constituem como um grupo de pressão no legislativo federal, cuja disposição ao diálogo é escassa ou limitada sobre temas divergentes aos seus paradigmas litúrgicos.

O número de parlamentares vinculados as igrejas pentecostais é razoavelmente expressivo na Câmara dos Deputados, 94 do total de 513 deputados, não obstante acreditamos que seu poder de influência não está atrelado apenas a sua expressão numérica, mas a sua forma de atuação. Neste sentido, o crescimento da "bancada evangélica" possibilitou a este segmento grande poder de barganha, por meio de alianças e compromissos com diferentes setores e lideranças da vida partidária e política nacional.

A atuação corporativa destes parlamentares e sua pulverização no sistema partidário permitem às demais forças a percepção de um grupo coletivo minimamente organizado e com propósito definido, suficientemente capaz de arregimentar suas alianças políticas para desfazer maiorias no Poder Legislativo, por conseguinte, obstruir ações do Poder Executivo. Até mesmo, em situações limite, provocar o impeachment do/a chefe do Poder Executivo, como ocorreu com Dilma Rousseff (PT), cujo processo teve como principal organizador o Presidente da Câmara dos Deputados, o parlamentar Eduardo Cunha (PMDB-RJ), vinculado inicialmente a Igreja Sara Nossa Terra, e posteriormente a Assembleia de Deus.

Conforme já dito, as proposições políticas em prol da cidadania LGBTTQ e dos direitos reprodutivos das mulheres se transformaram em indicadores relevantes para verificar o poder de mobilização destes representantes políticos. Por meio de iniciativas políticas dessa natureza foi possível perceber com nitidez a influência deste segmento para pressionar o Poder Executivo, o Poder Legislativo, instâncias jurídicas e a opinião pública, no sentido de frear e deslegitimar deliberações sobre questões morais.

Este "lobby moral" restringe e impõe obstáculos à democracia brasileira para pensar agendas no campo dos direitos humanos. Este expedien- 
te é central para a vitalidade da democracia, pois a ampliação de direitos às minorias tornou-se tema de primeira importância para a legitimidade dos sistemas democráticos. Isto porque, é consenso a existência de elementos estruturais que excluem historicamente as minorias étnicas, de gênero e sexuais de direitos sociais e políticos, por isso é imperativo a existência de políticas de correção destas injustiças. Na contramão de boa parte das democracias liberais do ocidente, a atuação dos pentecostais tornou a discussão destes temas quase um tabu no panorama político nacional.

Dessa forma, concordamos com a perspectiva de Ronald Dworkin, ou seja, de que é intolerável que a liberdade religiosa seja utilizada por grupos religiosos como artifício antidemocrático para justificar a subordinação de indivíduos/grupos. Para alterar este quadro, argumenta Ronald Dworkin, deve haver dispositivos jurídicos e políticos para regular os limites de atuação dessa liberdade. Porquanto a noção de liberdade religiosa sempre foi conduzida de modo desigual, pois mesmo sendo direito básico a todas as pessoas (inclusive dos ateus), este princípio respeita apenas a liberdade teístas, fornecendo subsídios defenderem posturas intolerantes.

Este cenário é um sinal para o apagamento no Brasil de valores fundamentais às democracias, como a laicidade do Estado. Este princípio jamais foi plenamente incorporado na formação das constituições brasileiras, todavia, o panorama apresentado permite vislumbrar a possibilidade de aprofundamento na relação entre Estado e as religiões cristãs.

\section{CONSIDERAÇÕES FINAIS}

Neste texto procuramos analisar os incentivos para o ingresso na política das igrejas pentecostais. Do mesmo modo, apresentamos hipóteses para compreender o processo de autorização política dos eleitores/fiéis aos candidatos apresentados por suas denominações, com base na idéia de que a fé e seus valores são responsáveis por engendrar uma perspectiva social, presente nas plataformas eleitorais dos representantes políticos. 
Para pensar a construção da representação política pelas igrejas pentecostais examinamos a formação e elaboração das estratégias político-eleitorais a partir do modelo institucional ou corporativo. Os dispositivos mobilizados pelas igrejas pentecostais fazem com que o mandato, até certo ponto, "pertença" à denominação. Neste caso, há definição de como se posicionar e a quem se devem prestar contas. A interferência institucional produz obstáculos para a criação de uma maior interlocução entre representante e representados. Sendo assim, os mecanismos de sanção efetiva dos eleitores/fiéis são modestos, restritos a (des) aprovação eleitoral aos candidatos por meio de seu voto.

O modelo institucional de representação e a atuação da "bancada evangélica" permitem entender este segmento religioso e político como grupo de interesse. Em virtude de sua organização para fins eleitorais ter como propósito a conquista de suas demandas ou preservação dos valores fundamentais a sua crença. É plausível aferir, também, que esta atuação se configura em potenciais riscos à democracia brasileira, pois os princípios e as demandas que alicerçam esta representação são corporativos e visam, por meio da pressão ao sistema político, a proteção dos interesses e valores morais de sustentação às sociedades religiosas em questão. Com isso, há imposição de limites para o aprofundamento da laicidade do Estado, e das liberdades laicas, elementos fundamentais para a legitimidade da democracia.

\section{REFERÊNCIAS BIBLIOGRÁFICAS}

Bohn, Simone. "Evangélicos no Brasil. Perfil sócio-econômico, afinidades ideológicas e determinantes do comportamento eleitoral". Revista Opinião Pública 10. 2 (2004): 288-338.

. "Contexto político-eleitoral, minorias religiosas e voto em pleitos presidenciais (2002-2006)". Revista Opinião Pública 13. 2 (2007): 366-387. 
Borges, Tiago DaAHer. Representação partidária e a presença dos evangélicos na política brasileira. Dissertação de Mestrado em Ciência Política. São Paulo: Universidade de São Paulo, 2007.

CAmpos, LeOnildo. "O Projeto político de "governo do justo": os recuos e avanços dos evangélicos nas eleições de 2006 e 2010 para a Câmara Federal". Revista Debates do NER 2. 18 (2010): 39-82.

Conrado, Flávio. Cidadãos do Reino de Deus: um estudo da "Folha Universal" nas eleições de 1998. Dissertação de Mestrado em Sociologia e Antropologia. Rio de Janeriro: Universidade Federal do Rio de Janeiro, 2000.

Dworkin, RONALD. Religion without god. Cambridge: Harvard University Press, 2013.

Filho, VAldemar Figueiredo. Entre o palanque e o púlpito: mídia, religião e política. Dissertação de Mestrado em Ciência Política. Rio de Janeiro: Universidade Federal do Rio de Janeiro, 2002.

FONSECA, ALEXANDRE BRASIL. Secularização, pluralismo religioso e democracia no Brasil: um estudo sobre os evangélicos na política nos anos 90. Tese de doutorado. Universidade de São Paulo, Brasil, 2002.

FPE (Frente Parlamentar Evangélica). Membros da FPE. Disponível em http://www.fpebrasil.com.br/portal/. [Acesso em: 30 jul.2018].

Freston, Paul. Religião e Política Sim; Igreja e Estado, Não: os evangélicos e a participação política. Minas Gerais: Editora Ultimato, 2006. Protestantes e política no Brasil: da Constituinte ao impeachment. Tese de d. São Paulo: Universidade Estadual de Campinas, 1993.

GERALDO, PEDRo. O senador e o bispo: as estratégias de construção identitária nas eleições municipais cariocas de 2004. Revista Religião e Sociedade 32. 1 (2012): 97-129.

Giumbelli, EMERSOn. O Fim da religião: dilemas da liberdade religiosa no Brasil e na França. São Paulo: Editora Attar, 2002.

LACERDA, FÁBIO. "Assessing the Strength of Pentecostal Churches' Electoral Support: Evidence from Brazil". Journal of Politics in Latin America. 10. 2 (2017): 3-40. 
MACEDO, EDIR. Nada a perder. Rio de Janeiro: Editora Unipro/Planeta, 2014.

Machado, Maria Das Dores. "Religião, Cultura e Política". Revista Religião e Sociedade 32.2 (2012): 29-56.

. "Discursos pentecostais em torno do aborto e da homossexualidade na sociedade brasileira. Revista Cultura y Religión. 7. 2 (2013): 48-68.

e JOANILDO BuRITY. "A Ascensão política dos pentecostais no Brasil na avaliação de líderes religiosos". Revista Dados. 57.3 (2014): 601-631.

MAINWARING, SCOTT. Igreja católica e política no Brasil. São Paulo: Editora Brasiliense, 1989.

Mariano, Ricardo. "A Reação dos evangélicos ao Código Civil". Revista Civitas 6.2 (2006): 77-99.

e AnTÔNIO Flávio PieruCCI. "O Envolvimento dos pentecostais na eleição de Collor". Revista Novos Estudos CEBRAP 34 (1992): 92106.

. "A Expansão neopentecostal no Brasil: o caso da Igreja Universal". Revista Estudos Avançados 18. .52 (2004): 2004.

Miguel, LuIS FeLIPE. Democracia e representação: territórios em disputa. São Paulo: Editora da Universidade Estadual Paulista, 2014.

Nicolau, JaIro. "O sistema eleitoral brasileiro". Em Sistema Político Brasileiro: uma introdução. Lúcia Avelar e Antônio Cintra (eds.). Rio de Janeiro: Fundação Konrad-Adenauer-Stiftung, 2006. 293-301.

NovaES, Regina. "A Divina política: notas sobre as relações delicadas entre religião e política". Revista da USP 49 (2001): 60-81.

ORO, ARI PEDRo. "A Política da Igreja Universal e seus reflexos nos campos religioso e político brasileiros". Revista Brasileira de Ciência Sociais 18. 53 (2003): 53-69.

. "Organização eclesial e eficácia política: o caso da Igreja Universal do Reino de Deus". Revista Civitas 3. 1 (2003a): 97-109.

SiepiersKi, PAulo. "Pós-pentecostalismo e política no Brasil". Revista Estudos Teológicos 37.1 (2997): 47-61. 
0 PROCESSO de REPRESENTAÇÃO POLÍtICA CONSTRUÍDO PELAS IGREJAS PENTECOSTAIS NO BRASIL

Young, IRIs. Inclusion and Democracy. Oxford: Oxford University Press, 2000.

. Justice and the politics of democracy. Princeton: Princeton University Press, 1990. 
